\title{
TECHNOLOGY ENHANCED INFORMAL LEARNING, INTERDISCIPLINARITY, AND CULTURAL HISTORICAL ACTIVITY THEORY
}

\author{
Madeleine Sclater ${ }^{1}$, Vic Lally ${ }^{2}$ \\ ${ }^{1}$ Glasgow School of Art (UNITED KINGDOM) \\ ${ }^{2}$ University of Glasgow (UNITED KINGDOM)
}

\begin{abstract}
This paper explores the role of theory and interdisciplinarity in Technology Enhanced Informal Learning, and the research community. We consider Cultural Historical Activity Theory (CHAT) but we strongly feel that our argument has broader application to the use of theory as part of the intellectual 'self-defence toolkit' that researchers and practitioners in the critical TEL community need to consider if they are to 'resist' the crises arising from educational globalisation. Theory offers us the history, scope, power, and language, that we need to be reflexively aware of both our own interests and those of others who are actors in the settings in which we are working. The paper arose from our concern to provide evidence that our work in virtual research communities (in the Inter-Life Project) - to help young people pursue their own research agendas and find their research 'voices' - was actually effective in serving their interests as well as our own.

Our research revealed the centrality of learning space, community support, and creative/visual artefact production in the sustainability of these communities. We illustrate the interactions across these realms through selected examples from our Inter-Life findings. We explore how an interdisciplinary approach in TEL can support the creative confluence of learning in science and the visual arts, serving diverse cultural communities of learners. Finally, we consider resistance to the large-scale industrialisation of TEL, and its ideologies, that seems to us to be a key issue in TEL research. For example, we are concerned by the potential for surveillance and control that is contained in the whole learning analytics movement in which so many TEL researchers are becoming involved.
\end{abstract}

Keywords: Art and Design Education practice, Interdisciplinarity, Cultural Historical Activity Theory (CHAT), virtual worlds.

\section{INTRODUCTION}

Nissani has argued that 'Interdisciplinarity typically applies to four realms: knowledge, research, education, and theory' [1]. Much Technology Enhanced Learning (TEL) research involves the interlocking and overlapping, discontinuities and synthesis, of these four realms. In part, it is this interdisciplinary crossing over between them that drives the creation of fresh vision and new opportunities - the fundamental prerequisites to the building of creative, flexible and adaptable learning systems and environments. Interdisciplinarity, at its most basic, brings together the distinctive components of at least two disciplines. In the case of the project described in this paper (Inter-Life) these included Fine Art, Art and Design, Education, Educational Psychology, Natural Sciences, and Computer Sciences.

This paper explores some of the interdisciplinary themes that emerged from the results of the InterLife Project (2008-2012) ([2], [3], [4], [5], [6], [7], [8], [9]). We identified the role of theory in our research - Cultural Historical Activity Theory (CHAT), and socio-cultural pedagogic theory, in our learning activities, as central to our research into the development of a youth 'virtual research community' in Inter-Life. Our research also revealed the centrality of learning spaces and community. Firstly, we illustrate the interdisciplinary nature of our theorising about community and space. We also explore how our interdisciplinary approach in TEL can support the creative confluence of learning in science and the visual arts, serving diverse cultural communities of learners. We contend that the active seeking of interdisciplinarity and its broader, yet specific, application to TEL can offer us the language, history, scope, and theory that we need to develop flexible and adaptable TEL environments. 


\section{THE INTER-LIFE PROJECT}

The Inter-Life Project (Economic and Social Research Council/Engineering and Physical Sciences Research Council) was conducted between 2008 and 2012 in the UK and Trinidad. It was an interdisciplinary project involving researchers with divergent backgrounds in a project that was complex, as well as conceptual, methodological and theoretical. The work of the project was at the intersection of the contributing disciplines, and this impacted on the practical research activities of the project. The project focused on the development of an integrated inter-cultural 'context' in a 3D platform (Second Life ${ }^{\mathrm{TM}}$ ) in order to investigate how young people could use it creatively to assist in understanding and navigating their key life transitions. The central aim of Inter-Life was to create a community space or 'youth centre' in a modern and engaging online environment, where young people could pursue their own research agendas. The team chose to work with virtual reality in a 'virtual world'. Virtual worlds are avatar-based and networked social spaces. Avatars in this context are animated graphic representations of participants that can move around in the virtual world under users' control. They are often in human form but can be animals, birds, or other entities. They can be modified by participants at will. The world itself is constructed and shaped by the participants (see Figure 1: a meeting space on the beach in one of the Inter-Life Islands with interactive display boards floating in the air). Avatars can fly and 'teleport' from one part of the world to another. They can communicate with one another using gesture, text and real audio. These features build upon the reality that is already familiar to all of us, but they also extend it in imaginative and highly engaging ways - an aspect of virtual worlds that Thomas and Brown have called the 'networked imagination' [10]. To summarise, open-ended virtual worlds (of the type featured in this paper) are 'persistent social spaces that provide players or participants with the ability to engage in long term, coordinated conjoined action' ([10] p.37). Inter-Life created a highly visual and engaging online game environment where the participants make up the rules, design the game and customise the gaming environment. We attempted to work with young people as participant 'co-researchers' in a 'Virtual Research Community' (VRC) created in our virtual world. In this co-research, the adult research team was encouraging the young people to develop their own research agenda.

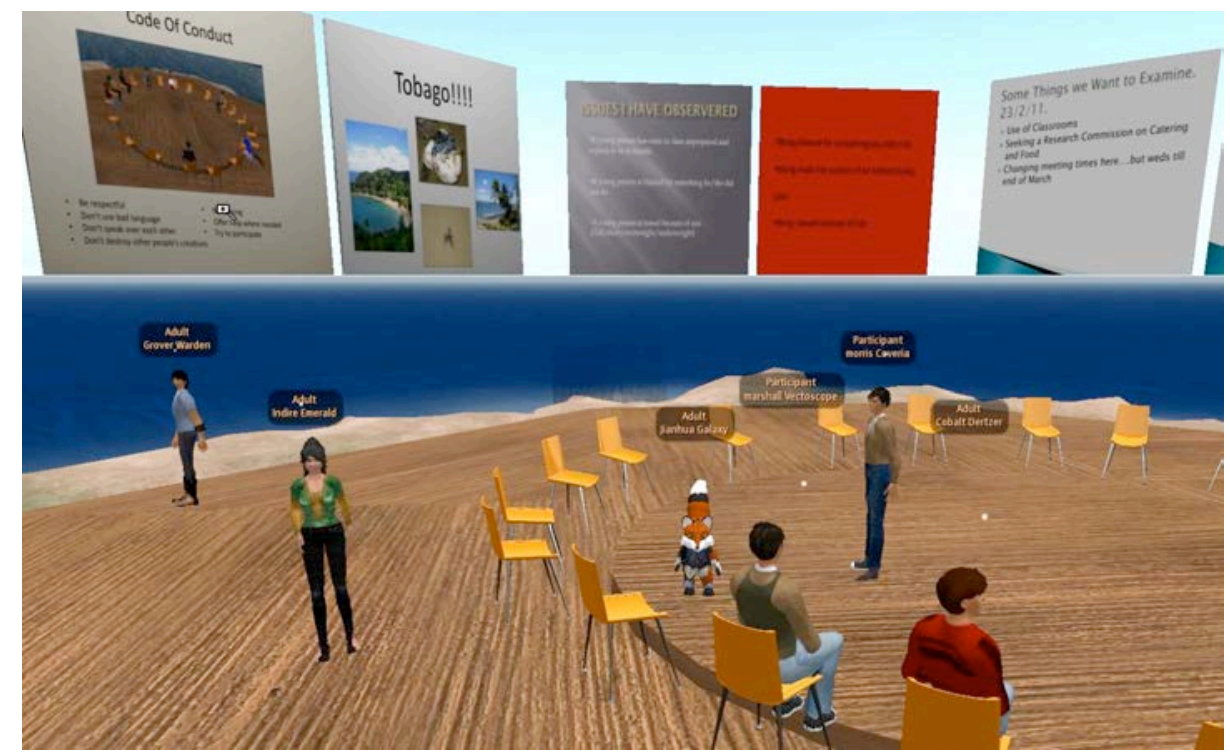

Fig. 1. Inter-Life meeting space on the beach, with interactive boards.

\section{THE INTER-LIFE PROJECT AND INTERDISCIPLINARY THEORY}

The Inter-Life Project needed an interdisciplinary theoretical framework that would be powerful enough to help us understand and analyse the activities of the young people with whom we worked. Cultural Historical Activity Theory (CHAT) was identified as a promising candidate using an approach to theory selection developed by Halverson [11]. CHAT focuses on the constituent influences on activity and places the participants and their goals centrally in 'systems of activity'. These systems include the tools used by young people, their motivations and goals, ideas and values, the community context and the artefacts that they create. Within this general framework, we focused on creative practices as tools to support reflection on social justice issues, the use of a virtual world as a community context and the 
development of young people's voices through creative practices as goals. The young people with whom we worked co-opted the tools and community setting for their own use and began to articulate their own goals during the project 'workshops'. One of the key issues we faced in the Inter-Life project was to take account of the complexities of the activities. We decided to use CHAT because we think it offers the possibility of systematically integrating the key components of learning in virtual worlds: tool development and mediation; internalisation of social knowledge; and transformations of the structures of human activity as it arises from learning and development [12]. In particular, third generation AT [13] recognises and attempts to address the challenges of understanding dialogue and the multiple perspectives of participants. It also seeks to understand the complexity of interacting 'activity systems' as those engaged in joint projects seek to develop their goals. CHAT is also concerned with 'objects' and the activities that are driven by them [14]. Objects can be concerns, foci of attention, or motivation to achieve a goal. Such objects can change in nature - what Engeström has called 'benign' runaway objects - and transcend boundaries, yield intermediate products and be visible, accessible and cumulative. They allow participants to return time and again, and engage in exchange and feedback with one another [14]. CHAT provides a coherent theoretical framework that connects the 'aims' of our young people, co-constructed through negotiation with the research team, with the spaces we are calling 'virtual communities'. The 'boundaries' in these spaces are between the school 'activity system' and the home 'activity system'. The unit of analysis, then, is not one or other, or both, of these activity systems but rather the boundary space between them where the young people are attempting to create artefacts (films, photographs and discussions in the virtual community) that explore their concerns and address their sense of justice. Roth [15] argues that emotions and identity are an integral part of this analysis, and understanding action level emotion ('actions' are the subactivity processes that constitute an activity) may help with understanding activity level motives. Third generation CHAT expands the analysis in two directions, tackling both multiple activity systems and their partially shared objects. It also tackles subjectivity, experiencing, personal sense, embodiment and moral commitment. The challenge, Engeström [14] points out, is to integrate analyses of multiple activity systems and their partially shared objects (films, photographs, and discussions in the virtual community, in this case). We argue that creativity arising from film-making and photography, and the shared emotional explorations that resulted, can be enabled by a novel space where some of the boundaries of traditional spaces are removed. Thinking can be opened up. A zone of proximal development, as Inter-Life might also be described, is a place for exploration rather than achievement. It is not an empty space but is derived from home and school. However, because it is a boundary space, it more easily permits the possibility of change, creativity and growth. This thinking is exemplified in an excerpt from an interview at the start of the project, when one of the Inter-Life team members commented:

\begin{abstract}
'I think a lot of educational spaces that exist are deeply constrained by social, cultural and political forces that mostly don't want them to be exploratory spaces and have very restricted views of knowledge creation...and don't want to accommodate a mixing of the social, emotional, and cognitive, whereas I think a lot of our learning is a mixture of all three of those....and so as an educator I was attracted to Second Life as a space where that possibility exists...'
\end{abstract}

(Educational Researcher in Inter-Life Team, 22 March 2009)

\title{
4 INFORMAL LEARNING COMMUNITIES
}

The realisation and implementation of the idea of community, as a basis for informal learning, was central to the Inter-Life project [16]. It was one of the key aims of the project to create informal virtual research communities (VRCs) for joint working, creation and discussions. CHAT helped us to focus on community as a key aspect of joint activity. Control was negotiated in an on-going way between the young people and the research team. This was an open conversation from the start. We were investigating ways in which the VRCs that developed within Inter-Life helped young people to acquire and develop skills to enhance their navigation of important life events in the real world. The young people were investigating a wide range of life issues significant to their own agendas. We co-inhabited the virtual island spaces. Researchers from the Inter-Life project worked with two distinct and separate communities on ILI2 [6]. One of the younger communities that was formed comprised young people living in local authority care in Glasgow and Sheffield (ages 13 to 17+) and a second comprised a small group of young people and their teacher in Trinidad (young people also ages 13 to 17+). One of the ways in which the research team endeavoured to relate to the young people and their youth agendas was to work alongside participants to develop their community and help them to express their 
'voices'. Researchers from the Inter-Life team engaged with each separate community in a series of co-designed activities involving engagement in 'creative practices' such as digital storytelling, filmmaking and photography, in order to explore important issues of individual and collective concern. These related to the social and emotional challenges of real world life events - such as moving from school into higher education, and strategies for tackling bullying. In the case of some of the participants, relocating to a new local authority/foster home, changing schools, making new friends and dealing with family bereavement were key events that they actively wanted to discuss in the community. Creative practices were used as a vehicle to enable young people to access and develop shared narratives about these issues as they worked together with researchers over an extended period on ILI2 ([6] p. 498).

From a CHAT perspective, we were interested in how participants acted and developed in the InterLife VRC while engaged in a series of co-designed creative and research activities mediated by tools (e.g. film technologies). We wanted to explore what, in reality, happens within these community spaces, and what meaning participants made of their activity within these spaces over a sustained period. This included probing how skills and understandings - that were developed as a consequence of engaging in a range of creative activities within Inter-Life community over time - mapped onto the real world. We were also particularly interested in researching how the VRC acted as an authentic context (that we supported and mentored) for participants in sustained engagement with a range of creative activities. We also looked at how the acquisition of new ideas (in this context, new insights, and new perspectives) helped participants to reconfigure the way they looked at the world beyond, while simultaneously engaged in activity in the VRC. We were interested in the dialogue, emotions and multiple perspectives that can be created and expressed in such a space, and the way in which young people's identities were forged and changed within this community. The research team were interested in understanding the mediating influence of creative practices as tools to support reflection on a wide range of informal educational aims, including those relating in particular, to social justice and the development of young people's own authentic voices. What both of these VRCs had in common is that they could provide a space for the development of shared values through the provision of mutual support, shared thinking and shared goals - what Engeström referred to as "benign run away objects." As previously mentioned "objects" within the context of the Inter-Life project were participants' concerns, motivations and goals. These were largely realised through artefacts (film, photography, narrative, written dialogue), that were capable of transcending boundaries and which were also visible, accessible and cumulable within the community ([6] p. 481). Participants were able to return time and again to these artefacts - leading inevitably to the evolution and transformation of the objects themselves and creating a real history. The artefacts became drivers of iterative action as well as a focus for exchange and feedback with participants in the community ([14], [6] p. 481). In this way, over time, the two communities developed and transformed into real research communities, by way of their interactions, and engagement with the development of artefacts (objects). These "objects" mediated activity in the community and created a focus for future action - in other words they helped to animate activity. The VRC that was developed might therefore be described as a "creative sounding board" for the expression of these new insights and perspectives, mediated through the tools (e.g. technologies) and activities (creative practices), and resulting in the development of individually and collaboratively produced artefacts (sculptures, film, photography, fashion). The community acted as a (cultural) resource and, to some degree, a "safe place," since it was highly supported by mentors, enabling participants to engage in an iterative process of reflection, re-interpretation, re-evaluation and re-integration of the social, emotional and cognitive aspects of their "in world" experiences. The InterLife Project demonstrated both the role and importance of research communities; that is people working together on joint enterprise/s, dedicated to using a joint set of tools (creative tools in this case, e.g. cameras, video cameras, software, virtual world) to investigate an issue or set of issues in a systematic way, and to be able share the results (with outsiders and those in the group) in order to improve practices that are important to the community [16].

\section{THE SIGNIFICANCE OF LEARNING SPACES}

Communities need shared spaces in which to act, be, and develop. As indicated earlier, the Inter-Life project focused on the development of an integrated learning space ([9] pp. 3-4) in a 3D virtual world, in order to understand how this space could be used creatively by individuals and the group (using the practices of Art and Design education), to assist young people in exploring and acquiring specific skills to navigate their key life transitions. For example, our learning space supported creative practices and creative expression, ranging from creating sculpture through multiple changes of one's avatar appearance, to being able to modify the landscape, teleport, fly and use collaborative tools ([17], [9] p. 
12). It was therefore possible to transform the space into a sophisticated personalised environment, which was used as an informal educational setting for a variety of creative endeavours. In effect, we created a virtual youth centre in a contemporary and creative online space where the young people, supported by the research team, could engage in the kinds of activities described and pursue their own interests and research plans ([9] p. 3). The possibilities afforded by the space formed the basis of initial discussions that led to the development of each community exploring, defining and negotiating the rules governing the space. The island provided the illusion of a large open space - offering a natural setting in which participants could act, develop and also extensively explore. At the inception of the project a few rudimentary buildings were put in place to give the space some physical structure, and to provide some starting points for action. As the project progressed, and participants became increasingly engaged in pursuing their own agendas, the space became populated by other structures, objects and artefacts. For example, one of the young people, who was part of the Trinidad/Sheffield group, made much creative use of the scripting system, and being somewhat of a non-conformist in the group, introduced several objects into the space - such as enormous chairs and jellyfish. These interrupted the group's activities and discussion in playful ways ([6] p. 488). The emotional and affective dimensions of learning have been highlighted in relation to the development of educational spaces ([18], [9] p. 12). Research from the Inter-Life project argues that virtual worlds can facilitate the expression of the affective aspects of our selves and, in so doing, offer positive emotional spaces for learning. For example, when discussing the ability to present oneself as an avatar with a customisable appearance, one of the participants suggested that this enhanced his interest and engagement in the Inter-Life space, as he gradually refined his avatar so that it "felt" like him ([6] p. 492). He mentioned that the Inter-Life Island space had helped him find out about what his real capabilities were; he had found Inter-Life Island to be a place where he could work, where he was comfortable with the atmosphere it produced, and the possibilities for creativity that it fostered. "It's an open environment, and if you want to do something you can" (interview) ([6] p. 492). In the research interviews, participants' interaction with the space and its features, through play and socialisation, were key experiences reported ([6] p. 497). Therefore, we argued that the ability to engage in forms of selfexpression, socialisation and play within these learning spaces were key in driving the engagement with the space over time. Initially we conceived of Inter-Life as a kind of "transitional space" ([9] p. 12, [19]), or a place of mediation ([6]p. 482), in which dimensions of the self can be created as well as transformed in relationship with others in a setting. In CHAT terms, Inter-Life and its two communities were initially a kind of a "boundary space" between the home and school activity systems. However, it developed as an independent activity system, parallel to home and school. This "boundary space" effectively metamorphosed into an entirely new activity system over time with its own values and tools - a place that began to open up new possibilities for "being" and consequently expanding the horizons of what might be possible ([6] p. 482). In Engeström's terms, this new space, claimed and developed by the young people, could be regarded as a "benign runaway object" (goal) of the project. Learning space in the Inter-Life Project was contested (e.g. the island was literally turned upside down), personalised, and collaboratively developed. Researchers and young people could move through it in ways that are not possible in the real world, for example flying, teleporting and walking under water. Therefore, the space could be structured and restructured in imaginative ways that supported the goals and intentions of the group. The space was contingent upon the wishes and intentions of the group - it was not pre-determined and neither were the activities within it. It contained the representations of ideas, projects and thinking and became a site of collective memory with its own history; it was not created instantly. It became a cultural context, a site for meaning making which supported and drove activity as well as offering a place for learning and discovery - a place to play, a home (a place of familiarity) and, to some, extent safety. The virtual learning space mediated "closeness" among members of the community and, in the process, dissolved national and international boundaries, resulting in a form of activity that hitherto would not have been feasible. The learning space helped young people to explore issues; we advised, stepped back, we talked, we interviewed, and we let the young people pursue their agendas, and brought their research into the foreground. These agendas were not always compatible with the researchers' agendas. But two distinct research agendas were certainly possible in this space. Inter-Life became 'a commons': a space shared by all the members of the community. Group activities were linked to the characteristics of a space, and they were interlinked with one another. Hence ownership of the space and how it is shared became very much determinants of the nature of activity. 


\section{TALKING WITH AN INTERDISCIPLINARY TEAM}

During the Inter-Life Project, we interviewed members of the team about their experiences of working in an interdisciplinary research group that included researchers from Fine Art, Education, Art and Design Education, Computer Science, Natural Science, Educational Psychology, Technology Education and Computer Science. One of the challenges of the project had been to find a common language that would enable us to cohere around the research goals. As we have indicated in the account above, CHAT eventually became the interdisciplinary theoretical basis of the project. One researcher said:

\section{'Activity theory makes possible some sort of coherent approach...'}

(Educational Researcher, 22 March 2009)

Much of our discussion focused on methodology, and these conversations were both productive and perplexing: 'How do we resolve the very big methodological differences between social scientists and
computer scientists? Can we? Should we?'

(Educational researcher, 22 March 2009)

'We have the opportunity to automate our data gathering...and do original educational research. It's interesting and a challenge. The data might be too crude. We might get lost in a haze of data.'

(Technology Educator 3 April 2009)

Another issue was that each researcher was also connected to her/his wider disciplinary network, and this was sometimes a moderating influence on our interdisciplinary ambitions:

'Some psychologists l've talked to think our aspirations are ridiculous...As a researcher, I have a different perspective...'

(Educational Psychologist 24 March, 2009)

The biggest challenge, however, was that the range of expertise could be very stimulating and perplexing at the same time:

'I have found this an interesting experience. I didn't realize how difficult it would be to work with people from so many backgrounds.'

(Art and Design Educator 24 March 2009)

'The challenge of getting on the same page with people working with different paradigms... The challenge has been to communicate what we are trying to achieve in an educational sense...l have felt it tremendously valuable and supportive, and the different ways of thinking bring up new ideas...'

(Art and Design Educator 24 March 2009)

'The focus is in the educational domain...but innovation needs to straddle the Computer Science and the Education components...'

(Technology Educator 3 April 2009)

\section{DISCUSSION AND CONCLUSIONS}

This paper summarises some of our key interdisciplinary concerns and interests from Inter-Life. We have considered how an interdisciplinary approach can offer the possibility of creative interactions between different disciplinary researchers in a TEL research project. The interdisciplinary Inter-Life TEL project encountered a strong need for a shared language with which researchers could explore and exchange ideas with one another, and bridge the complexity of working across disciplines. This was partly achieved through the use of CHAT. Themes of community and space also emerged from the work of the project team. These were illuminated as objects of research by CHAT, as well as being, in part, the result of the creative tensions that were a key part of the interdisciplinary interactions of team members. The resulting creative interplay of theory, community and space are illustrated. We contest that explicit, conscious and reflective interdisciplinarity may become a key 
factor in the future development of flexible and personalised solutions to some of the challenges faced by TEL researchers and developers.

\section{ACKNOWLEDGEMENTS}

This work was made possible by generous funding from the Economic and Social Research Council (ESRC, UK) and the Engineering and Physical Sciences Research Council (EPSRC, UK) [RES-13925-0402]. Many researchers and young people contributed to the Inter-Life Project. We are deeply grateful for all of these contributions, and the positive criticism and suggestions for improvement offered by these and many other collaborators and colleagues.

\section{REFERENCES}

[1] Nissani, M. (1997) Ten cheers for interdisciplinarity: The case for interdisciplinary knowledge and research. The Social Science Journal, 34(2), 201-216.

[2] Devlin, A.M., Lally, V., Canavan, B. \& Magill, J. (2013) The role of the Inter-Life virtual world as a creative technology to support student transition into higher education, Creative Education, 4(7b), pp. 191-201. Funded by EPSRC/ESRC RES-139-25-0402.

[3] Devlin, A. M., Lally, V., Sclater, M. and Parussel, K. (2013) Inter-Life: A Novel, Threedimensional, Virtual Learning Environment for Life Transition Skills Learning. Interactive Learning Environments 21 pp 1-22. Funded by EPSRC/ESRC RES-139-25-0402.

[4] Lally, V. and Doyle, L. (2012) Researching Transitions in Learning and Education: international perspectives on complex challenges and imaginative solutions (Editorial). Research in Comparative and International Education, 7(4), 394-408. Funded by EPSRC/ESRC RES-13925-0402.

[5] Lally, V, Sharples, M. Frances Tracy, F., Bertram, N. and Masters, S. (2012) Researching the Ethical Dimensions of Mobile, Ubiquitous and Immersive Technology Enhanced Learning (MUITEL): A Thematic Review and Dialogue. Interactive Learning Environments 20 (3) pp 217238. Funded by EPSRC/ESRC RES-139-25-0402.

[6] Lally, V., and M. Sclater, M. (2012) The Inter-Life Project: Inter-cultural Spaces for Young People to Use Creative Practices and Research to Assist with Life Changes and Transition. Research in Comparative and International Education 7 (4) 480-502. Funded by EPSRC/ESRC RES-139-25-0402.

[7] Lally, V, and Sclater, M. (2013) The Inter-Life Project: Researching the Potential of Art, Design and Virtual Worlds as a Vehicle for Assisting Young People with Key Life Changes and Transitions. British Journal of Guidance and Counselling 41 (3) pp 1-17. Funded by EPSRC/ESRC RES-139-25-0402.

[8] Sclater, M. and Lally, V. (2013) Virtual Voices: Exploring Creative Practices to Support Life Skills Development among Young People Working in a Virtual World Community. International Journal of Art \& Design Education 32 (3) 331-344.

[9] Sclater, M. and Lally, V. (2014) The Realities of Researching Alongside Virtual Youth in Late Modernity: Creative Practices and Activity Theory. Journal of Youth Studies 17 (1) 1-25. Funded by EPSRC/ESRC RES-139-25-0402.

[10] Thomas, D., \& Brown, J. S. (2009). Why virtual worlds can matter. International Journal of Learning and Media, 1, 37-49.

[11] Halverson, C. A. (2002). Activity theory and distributed cognition: Or what does CSCW need to DO with theories? Computer Supported Cooperative Work, 11, 243-267.

[12] Kaptelinin, V., \& Nardi, B. (2006). Acting with technology: Activity theory and interaction design. London: MIT Press.

[13] Engeström, Y. (2001). Expansive learning at work: Towards an activity theoretical reconceptualisation. Journal of Education and Work, 14, 133-156. 
[14] Engeström, Y. (2009). The future of activity theory: A rough draft. In A. Sannino, H. Daniels \& K. D. Gutierrez (Eds.), Learning and expanding with activity theory (pp. 303-328). Cambridge: Cambridge University Press.

[15] Roth, W.-M. (2008). Participation, learning, and identity: Dialectical perspectives. Berlin: Lehmann's Media.

[16] Sclater and Lally 2016.

[17] Doyle, D. (2010). Immersed in learning: Supporting creative practice in virtual worlds. Learning, Media and Technology, 35, 99-110.

[18] Sagan, O. (2008). Playgrounds, studios and hiding places: emotional exchange in creative learning spaces. Art, Design \& Communication in Higher Education, 6(3) 173-186. 